\title{
Survivin and XIAP: two valuable biomarkers in medullary thyroid carcinoma
}

\author{
Thomas A Werner ${ }^{1}$, Yasemin Tamkan-Ölcek ${ }^{1}$, Levent Dizdar ${ }^{1}$, Jasmin C Riemer ${ }^{2}$, Achim Wolf ${ }^{1,3}$, \\ Kenko Cupisti ${ }^{1,4}$, Pablo E Verde ${ }^{5}$, Wolfram T Knoefel ${ }^{1}$ and Andreas Krieg ${ }^{*, 1}$ \\ ${ }^{1}$ Department of Surgery (A), Heinrich-Heine-University and University Hospital Duesseldorf, Building 12.46, Moorenstrasse 5, \\ Duesseldorf, Germany; ${ }^{2}$ Institute of Pathology, Heinrich-Heine-University and University Hospital Duesseldorf, Duesseldorf, \\ Germany; ${ }^{3}$ Department of Surgery I, Ingolstadt Medical Center, Ingolstadt, Germany; ${ }^{4}$ Department of Surgery, Marien-Hospital \\ Euskirchen, Euskirchen, Germany and ${ }^{5}$ Coordination Center for Clinical Trials, Heinrich-Heine-University and University Hospital \\ Duesseldorf, Duesseldorf, Germany
}

\begin{abstract}
Background: Medullary thyroid carcinoma (MTC) accounts for 5\% of all thyroid malignancies. To date, surgery is the first-line therapy with curative intention. However, for advanced MTC, conventional chemotherapeutic agents do not provide convincing results. Therefore, the identification of biomarkers that can be antagonised by small-molecule therapeutics may lead to novel encouraging treatment options.
\end{abstract}

Methods: Seventy-nine patients with surgically resected and histologically confirmed MTC were included in this study. Tissue microarrays were constructed to assess the relationship between inhibitor of apoptosis proteins (IAPs) survivin or XIAP expression levels and clinicopathological variables as well as overall survival.

Results: High survivin or XIAP expression was associated with an advanced T-stage and metastatic disease. Whereas tissue expression levels of survivin correlated with serum calcitonin levels, XIAP was overexpressed in the subgroup of patients with sporadic MTC. Both IAPs were negatively associated with patient survival in the multivariate Cox regressions analysis (survivin: hazard ratio (HR) 1.62; 95\% confidence interval (Cl): 1.21-2.16; $P=0.001$; XIAP: HR 1.78; 95\% Cl: 1.16-2.72; $P=0.008$ ).

Conclusions: Survivin and XIAP demonstrate distinct expression patterns in MTCs, which are associated with advanced disease and poor prognosis. We thus provide first evidence that both IAPs might serve as viable targets in patients with MTC.

Medullary thyroid carcinoma (MTC) originates from the calcitonin-secreting, non-iodine-retaining parafollicular $\mathrm{C}$ cells. It is the third most common thyroid malignancy and accounts for $\sim 5 \%$ of all thyroid carcinomas (Ball, 2009). Although 75\% of all MTCs occur sporadically, $\sim 25 \%$ of all patients harbour a germline mutation of the REarranged during Transfection (RET) protooncogene (Donis-Keller et al, 1993; Takahashi, 1995). The RET proto-oncogene is located on chromosome 10q11.2 and is essential for the regulation of cell cycle progression, migration and differentiation (Blume-Jensen and Hunter, 2001; Qi et al, 2011). Importantly, mutations of the RET gene are associated with three distinct clinical syndromes: multiple endocrine neoplasia type $2 \mathrm{~A}$ $(70 \%)$ and B (10\%) (MEN2A/B) and the non-MEN (20\%), also called familial MTC (FMTC). Although these germline mutations conclude in different syndrome-specific diseases such as pheochromocytoma and primary hyperparathyroidism for MEN2A and $B$, FMTC shows no other sign or symptom apart from MTC (Eng et al, 1996; Leboulleux et al, 2004; Wells et al, 2013).

However, for both groups of patients the adequate therapy upon establishing the diagnosis remains the radical thyroidectomy with or without lymphadenectomy depending on the clinical findings and the serum level of calcitonin (American Thyroid Association Guidelines Task Force et al, 2009; Dralle et al, 2013). Owing to the large group of patients that present with advanced metastatic disease at the time of initial diagnosis, adjuvant therapeutic strategies have been in the focus of researchers worldwide

*Correspondence: Dr A Krieg; E-mail: andreas.krieg@med.uni-duesseldorf.de

Received 30 October 2015; revised 7 December 2015; accepted 16 December 2015; published online 4 February 2016

(c) 2016 Cancer Research UK. All rights reserved 0007-0920/16 
(Tuttle et al, 2010). Hence, the better understanding of MTC tumour biology has led to the identification of new promising molecular targets like the tyrosine kinase receptors (Hu et al, 2014). These therapeutic targets can be affected by small molecular compounds, creating new options for the patients as well as the clinical team (Wu et al, 2011). However, despite first encouraging results of targeted therapy approaches, the prognosis of patients with distant metastases remains poor, with 10-year survival rates of $21 \%$ (American Thyroid Association Guidelines Task Force et al, 2009).

Consequently, there is still an urgent need to identify novel druggable molecular targets that are of relevance for MTC tumour biology. In this context, a group of antiapoptotic proteins referred to as the inhibitor of apoptosis protein (IAP) family has attracted considerable attention. Inhibitor of apoptosis proteins are a family of proteins defined by up to three baculoviral IAP repeat (BIR) domains (Miller, 1999) that are necessary for protein-protein interaction with a number of proapoptotic factors (Gyrd-Hansen and Meier, 2010). They have an important role in cell death, mitosis, migration, metastasis and inflammation (Bertrand et al, 2009; Krieg et al, 2009; Krieg and Reed, 2010; Mehrotra et al, 2010; de Almagro and Vucic, 2012). So far, eight members of the human IAP family have been identified: NAIP (BIRC1), c-IAP1 (BIRC2), c-IAP2 (BIRC3), XIAP (BIRC4), survivin (BIRC5), Apollon/Bruce (BIRC6), ML-IAP (BIRC7) and ILP-2 (BIRC8) (de Almagro and Vucic, 2012).

Two of the most renowned IAP-family members survivin and XIAP synergistically inhibit apoptosis by forming a complex that prevents XIAP from proteasomal degradation, resulting in an enhanced inhibition of caspases (Vaux and Silke, 2003). Moreover, survivin-XIAP interaction promotes tumour cell invasion and metastasis by inducing nuclear translocation of transcription factor nuclear factor $-\kappa \mathrm{B}(\mathrm{NF}-\kappa \mathrm{B})$, which leads to the activation of cell motility kinases FAK (focal adhesion kinase) and Src (sarcoma) (Mehrotra et al, 2010). Whereas XIAP additionally inhibits the Ripoptosome, a $\sim 2 \mathrm{MDa}$ large cell death-inducing platform that mediates apoptosis and necroptosis in response to genotoxic stress (Tenev et al, 2011), survivin is involved in the formation of the chromosomal passenger complex, making it a key regulator of cell cycle progression that is essential for completion of mitosis (Rosa et al, 2006).

Importantly, overexpression of XIAP and survivin has been demonstrated to be associated with a poor prognosis in several types of tumours such as carcinomas of the colon, stomach, breast and kidney, making them potential biomarkers for these tumour entities (Mizutani et al, 2007; Goossens-Beumer et al, 2014; $\mathrm{Gu}$ et al, 2014; $\mathrm{Xu}$ et al, 2014). In addition, overexpression of survivin and survivin $\Delta \mathrm{Ex} 3$ splice variant has been demonstrated in thyroid malignancies, including a small number of MTC tissue specimens (Waligórska-Stachura et al, 2014).

Thus, the aim of our study was to determine the expression of survivin and XIAP in surgically resected specimens of MTC and corresponding normal thyroid tissue. Considering the synergistic function of XIAP and survivin, we aimed to assess the prognostic value of both IAPs in a rigorous manner according to the REporting recommendations for tumour MARKer prognostic studies (REMARK), as well as their association with clinicopathological characteristics of MTC patients (McShane et al, 2005).

\section{MATERIALS AND METHODS}

Patient selection. Patients who underwent curative surgery for histologically confirmed MTC at the Department of Surgery (A), University Hospital Duesseldorf between 1986 and 2003 were retrospectively reviewed. All types of primary thyroid surgery, with or without lymph node dissection, were included (i.e., thyroidectomy, hemithyroidectomy, subtotal resection). Exclusion criteria were incomplete pathological report or clinical data as well as macroscopic incomplete resection, or insufficient tumour material for further analysis. In addition, patients lost to follow-up or who died because of postoperative complications within the first 30 days after surgery were excluded for survival analysis. The study was conducted according to Good Clinical Practice, the Declaration of Helsinki and local rules as well as regulations of the country. In addition, strict anonymity of all study data were established and maintained. Moreover, the study was carried out with an ethical approval from the institutional ethics committee of the Medical Faculty, Heinrich Heine University Duesseldorf (reference number: 3821).

Clinicopathological data. Overall survival data were obtained from our prospectively maintained clinical database. Clinical parameters including age at first diagnosis, gender, date and type of surgery, serum calcitonin levels before surgery, family history and results from genotyping with regard to sporadic and inherited MTC, initial tumour stage including TNM status, affected lobe and clinical follow-up were retrospectively reviewed. Pathological findings were directly obtained from the original histopathology reports. All tumours were staged according to the 7 th edition of the UICC classification (Ito et al, 2012). Samples from earlier surgeries were adjusted to this staging system to ensure conformity and reproducibility.

Tissue microarray and immunohistochemistry. All formalinfixed paraffin-embedded tissue blocks were retrieved from the Institute of Pathology, University Hospital Duesseldorf. A total of nine TMA paraffin blocks were constructed for this study. They contained each two representative tissue cores of the primary tumour, one tissue core of normal thyroid gland, two tissue samples of a lymph node metastasis if present and one tissue sample of distant metastasis if available for each respective patient. Accordingly, for each patient up to six cylinders of $1.0 \mathrm{~mm}$ diameter were taken from their respective donor blocks and placed in paraffin recipient blocks, with $0.5 \mathrm{~mm}$ distance between the cylinders. Finally, one TMA block consisted of a maximum number of 10 different patients and their respective tissue samples.

For immunohistochemical staining of survivin, XIAP and calcitonin, TMAs were cut into slides of $4 \mu \mathrm{m}$ thickness. The staining was performed using the ZytoChem Plus HRP-DAB Kit (Zytomed Systems, Berlin, Germany) as described previously (Cupisti et al, 2014). Briefly, after deparaffinisation and rehydration, antigen unmasking was performed at $95^{\circ} \mathrm{C}$ for $30 \mathrm{~min}$ using a $3 \%$ trisodium citrate dihydrate buffer equilibrated at $\mathrm{pH} 6$, followed by incubation for $20 \mathrm{~min}$ at room temperature. Endogenous peroxidase was inactivated by incubating the slides in $3 \%$ $\mathrm{H}_{2} \mathrm{O}_{2}$ in phosphate-buffered saline (PBS, $\mathrm{pH}$ 7.4) for $10 \mathrm{~min}$ at room temperature. Sections were then rinsed three times for $2 \mathrm{~min}$ in PBS with $0.1 \%$ Tween-20 (Sigma-Aldrich, St Louis, MO, USA), followed by blocking of unspecific protein binding sites using reagent 1 . After washing in PBS with $0.1 \%$ Tween-20, immunostaining was performed for $60 \mathrm{~min}$ at room temperature with rabbit polyclonal anti-survivin (NB500-201; 1:750 dilution; Novus, Littleton, CO, USA), mouse monoclonal anti-XIAP (Clone 48; 1:50 dilution; BD Biosciences, San Jose, CA, USA) and rabbit polyclonal anti-calcitonin antibody (Clone Poly29118, 1:100 dilution; Biolegend, San Diego, CA, USA), respectively. Isotype control was conducted using mouse IgG1 $\kappa$ (MOPC-21; 1:50 dilution; Abcam, Cambridge, UK) and rabbit immunoglobulin fraction (Code X0903; 1 : 1000 dilution; Dako, Glostrup, Denmark). After three washing steps in PBS with $0.1 \%$ Tween-20, slides were incubated with biotinylated secondary antibody and streptavidinHRP conjugate. Finally, colour development was achieved by incubation with $3,3^{\prime}$-diaminobenzidine high contrast and counterstaining with haematoxylin. To verify that all of the extracted MTC 
tissue cores contained tumour, we performed immunohistochemical staining against calcitonin. For each immunohistochemical staining procedure, a tissue slide of pretested human colon and renal cell carcinoma, known to express survivin or XIAP intensively, served as a positive control.

For TMA analyses, survivin and XIAP staining intensity and percentage of stained cells were scored by two independent investigators (TW and YT) according to the immunoreactivity score (IRS) reported by Remmele et al (1986) with slight modifications: intensity was graded as absent (0), weak/low (1), moderate (2) and high (3); percentage of stained cells was graded $<5 \%(0), 5-25 \%(1), 25-50 \%$ (2), $50-75 \%$ (3) and $>75 \%$ (4). The product of the two attributes equalled the IRS ranging from 0 to 12.

Statistical analysis. Differences in expression levels of survivin or XIAP according to clinicopathological variables were examined using the nonparametric Mann-Whitney test. Categorical data were analysed using the Fisher's exact test.

For survival analysis, survivin and XIAP were categorised into the groups of high expression ( $\geqslant$ median IRS) and low expression (<median IRS). Clinicopathological variables were compared as follows: T1/2 vs T3/4, UICC I/II vs UICC III/IV and age as well as calcitonin $\left(\mathrm{pmoll}^{-1}\right)$ based on their median $(\geqslant$ median vs $<$ median). Overall survival was defined as the period from the date of surgery until death of any causes or until the date of the last follow-up at which survivors were censored. For univariate survival analysis, survival curves were evaluated using Kaplan-Meier curves and assessed using the log-rank (Mantel Cox) test (GraphPad Software, La Jolla, CA, USA). Cox regression analysis was used for multivariate survival analyses, estimating hazard ratios (HRs) with 95\% confidence intervals (CIs). The regression analysis was first performed with all available variables and then focussed using a stepwise variable selection procedure based on the Akaike information criterion (AIC). Internal validation was conducted using Bootstrap analysis with 500 replicates.

In addition, as an exploratory analysis, we performed a survival regression tree analysis to identify subgroups of patients with a high risk of death. This technique combines an algorithm for recursive partitioning together with a well-defined theory of permutation tests. Multiple test procedures are applied to determine whether a significant association between any of the covariables and the response variable can be stated. The resulting partitioning regression analysis is graphically displayed as a classification tree. The partitioning nodes are displayed by an optimal cut-off point for continuous covariables and with a classification split for categorical covariables. Each node split is assessed with a $P$-value calculated by a permutation test.

Data analysis was performed using the Statistical Software $\mathrm{R}$ version 3.1.0 (R Development Core Team, 2014). A $P$-value $<0.05$ was considered to indicate statistical significance.

\section{RESULTS}

Patients and outcome. Based on our inclusion and exclusion criteria, a total number of 79 patients could be included in this study (Supplementary Figure 1). Patients' clinical and pathological characteristics are summarised in Table 1 . Because five patients were lost to follow-up, a total number of 74 patients were included for survival analysis. Median overall survival of these patients was 166 months (range 5-287 months).

Calcitonin basal blood levels were available for 59 patients before surgery. The median level being $459 \mathrm{pg} \mathrm{ml}^{-1}$. The genetic background of MTCs, whether sporadic or inherited, was known for 71 patients, whereas there was no clear indication for eight patients. The type of surgery differed depending on the given recommendation of the respective period of time. The vast
Table 1. Patient characteristics $(n=79)$

\begin{tabular}{|c|c|}
\hline Variables & No. of patients (\%) \\
\hline Total & 79 \\
\hline \multicolumn{2}{|l|}{ Age } \\
\hline Median (range); years & $49(6-83)$ \\
\hline \multicolumn{2}{|l|}{ Gender } \\
\hline Male & $38(48)$ \\
\hline Female & $41(52)$ \\
\hline \multicolumn{2}{|l|}{ Genetic } \\
\hline Sporadic & $37(47)$ \\
\hline MEN2A & $34(43)$ \\
\hline Unknown & $8(10)$ \\
\hline \multicolumn{2}{|c|}{ Basal calcitonin levels prior to surgery } \\
\hline$<12 \mathrm{pg} \mathrm{ml}^{-1}$ & $47(60)$ \\
\hline$>12 \mathrm{pg} \mathrm{ml}^{-1}$ & $12(15)$ \\
\hline Unknown & $20(25)$ \\
\hline \multicolumn{2}{|l|}{ Type of surgery } \\
\hline Hemithyroidectomy & $11(14)$ \\
\hline With unilateral ND & $3(4)$ \\
\hline Subtotal thyroidectomy & $3(4)$ \\
\hline With bilateral ND & $2(2)$ \\
\hline Total thyroidectomy without ND & $14(18)$ \\
\hline With unilateral ND & $16(20)$ \\
\hline With bilateral ND & $30(38)$ \\
\hline \multicolumn{2}{|l|}{ Side affected } \\
\hline Unilateral & $65(82)$ \\
\hline Bilateral & $14(18)$ \\
\hline \multicolumn{2}{|l|}{ Tumour stage } \\
\hline$T 1 / 2$ & $60(76)$ \\
\hline $\mathrm{T} 3 / 4$ & $19(24)$ \\
\hline \multicolumn{2}{|l|}{ Lymph node metastasis } \\
\hline NO & $37(47)$ \\
\hline $\mathrm{N} 1 \mathrm{a} / \mathrm{b}$ & $42(53)$ \\
\hline \multicolumn{2}{|l|}{ Distant metastasis } \\
\hline $\mathrm{MO}$ & $55(70)$ \\
\hline M1 & $24(30)$ \\
\hline \multicolumn{2}{|l|}{ UICC stage } \\
\hline $\mathrm{UICC} \mid / / I$ & $36(46)$ \\
\hline UICC III/IV & $43(54)$ \\
\hline
\end{tabular}

majority, however, was treated with a total thyroidectomy with or without neck dissection.

Survivin and XIAP expression correlate with advanced tumour stage. All included cores of primary tumour tissue as well as metastases stained positive for calcitonin, confirming the diagnosis of MTC. In addition, parafollicular C cells stained positively in normal thyroid tissue specimen (Figure 1). Next, we analysed the distribution of survivin and XIAP within the normal thyroid gland, MTCs and the corresponding lymph node or distant metastases. Whereas survivin and XIAP were strongly expressed in MTC with a predominately cytoplasmic localisation, normal thyroid tissue stained negative for both IAPs (Figure 1). However, when comparing primary MTC with their corresponding lymph node or distant metastasis, no difference in expression levels became evident (data not shown).

To explore a potential association between the two IAPs and clinicopathological parameters, two statistical approaches were applied. First, we compared the IRS across groups for each clinicopathological variable (i.e., UICC I+ II vs UICC III + IV; Figure 2).

Using this approach, we found a strong correlation between high survivin $(P=0.007)$ and XIAP $(P=0.001)$ expression levels 
and advanced UICC III/IV tumour stages (Figure 2C and G). Accordingly, IRSs for survivin were significantly higher in patients with T3/4 tumours (median: 12; range: $4-12$ ) when compared with T1/2 MTCs (median: 8; range: 0-12; $P=0.032$; Figure 2A). Additionally, tumour probes from patients with lymph node or distant metastasis showed a distinct higher expression of survivin compared with tumour probes from patients with non-metastasised disease stages $(P=0.007$ and 0.007 ; Figure 2B and $C)$. Interestingly, we also found a strong association between basal calcitonin blood levels and survivin expression. Patients with a high calcitonin blood level at the time of admission showed a significantly higher survivin expression in their respective primary tumour compared with patients with normal calcitonin blood levels $(P=0.047$; Figure 2D).

Similar results were obtained for the XIAP expression analysis. T3/4 samples demonstrated a significantly higher IRS for XIAP compared with T1/2 tumour samples $(P=0.002$; Figure $2 \mathrm{E})$. Again, a lymph node-positive status was also accompanied by

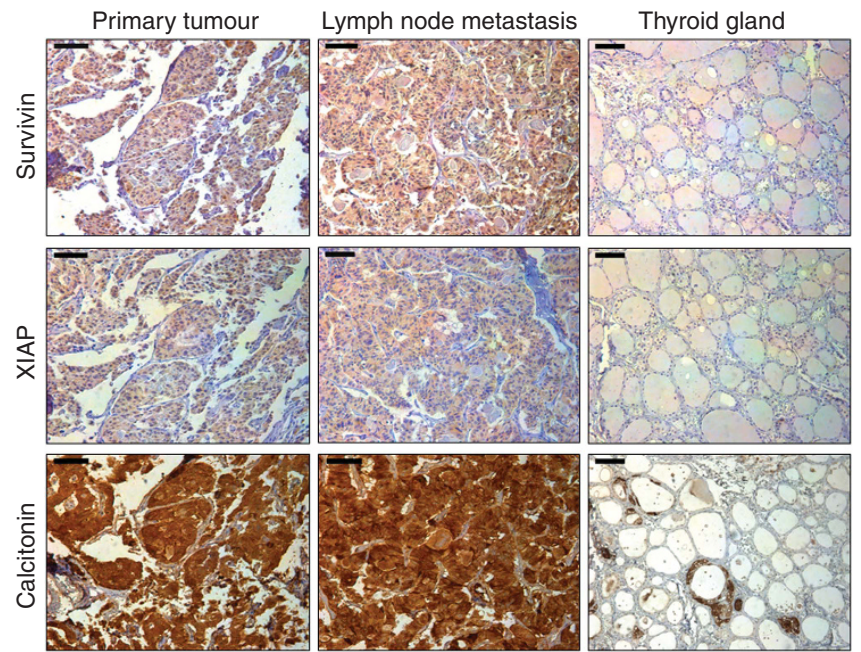

Figure 1. Representative tissue samples with immunohistochemical staining for survivin, XIAP and calcitonin in MTC (left), respective lymph node metastases (middle) and normal thyroid gland (right). All shown samples were classified as strong expression for the respective targets in accordance with the IRS. The bar at the top left corner indicates $50 \mu \mathrm{m}$. significantly higher expression of XIAP in the primary tumour $(P=0.001$; Figure 2F). Notably, patients with sporadic MTC also exhibited a distinct higher expression of XIAP as compared with the MEN2A-associated MTC $(P=0.032$; Figure $2 \mathrm{H})$.

Second, by categorising the respective expression levels according to the median into high ( $\geqslant$ median) and low ( $<$ median), we could confirm the association of high survivin and XIAP expression with more advanced tumour stages as well as an association of XIAP with sporadic MTC (Table 2).

Survivin and XIAP are independent markers of poor prognosis in MTC. For survival analysis, the following variables were included: age, gender, sporadic and inherited form, calcitonin basal blood level, tumour stage, lymph node status, distant metastasis and UICC stage as well as survivin and XIAP expression levels according to the IRS.

In the univariate analysis, high survivin $(\mathrm{HR}=3.765 ; 95 \% \mathrm{CI}$ : $1.166-6.568 ; P=0.021$ ) but not XIAP (HR $=1.239$; 95\% CI: $0.484-$ $3.140 ; P=0.662)$ expression was significantly associated with poor prognosis (Figure $3 \mathrm{~A}$ and $\mathrm{B}$, Table 3A). Clinicopathological variables such as old age at diagnosis, sporadic MTC, lymph node metastasis, M1 stage and the UICC stage predicted a worse outcome.

Next, we performed multivariate analysis using a stepwise variable selection procedure based on the AIC. Accordingly, advanced UICC stages III and IV ( $\mathrm{HR}=3.95$; 95\% CI: $1.143-$ $13.645 ; P=0.030)$ as well as sporadic disease $(\mathrm{HR}=5.815$; 95\% CI: $1.548-21.840 ; P=0.009)$ and high survivin expression $(\mathrm{HR}=1.616 ; 95 \% \mathrm{CI}: 1.207-2.162 ; P=0.001)$ were found to be independent prognostic factors for MTC (Table 3B). Interestingly, high XIAP expression levels became significant on multivariate analysis $(\mathrm{HR}=1.776 ; 95 \% \mathrm{CI}: 1.162-2.715 ; P=0.008)$, reflecting a prognostic relevance of XIAP in MTC disease. For a better visualisation, the regression estimates of the multivariate analysis are illustrated in Figure 3C after $\ln$ transformation.

Correlation between biomarkers. To further elucidate a possible interaction between survivin, XIAP and other clinicopathological markers, we performed a regression tree analysis. This test procedure allows the identification of specific biomarker constellations under which patients have a high risk of death. Interestingly, we found a subgroup of patients in our cohort that was associated with a distinct deterioration of their prognosis. Patients with a calcitonin basal blood level at the time of diagnosis below $596 \mathrm{pg} \mathrm{ml}^{-1}$, low survivin expression $($ IRS $<5)$, but high XIAP
A

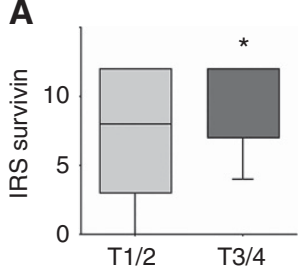

E

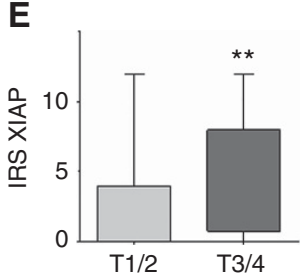

B

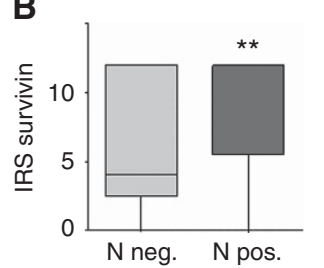

$\mathbf{F}$

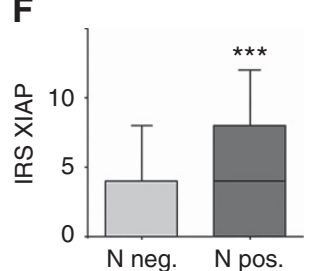

C

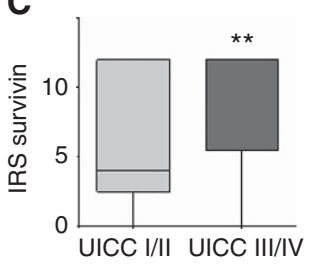

G

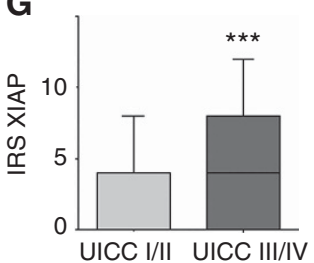

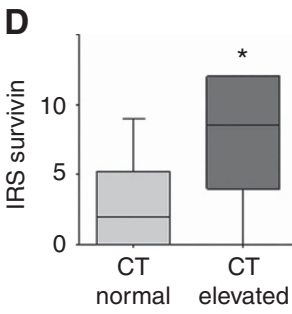

H

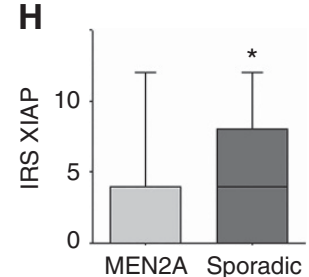

Figure 2. (A-H) Expression levels of survivin and XIAP and their association with clinicopathological variables in MTC. Boxplots display the median IRS with the upper and lower quartile, as well as maximum and minimum stratified according to the respective clinicopathological variable. $\mathrm{CT}=$ calcitonin. ${ }^{\star} P<0.05 ;{ }^{* \star} P<0.01 ;{ }^{* \star \star} P<0.001$. 
Table 2. Correlation between survivin or XIAP expression and clinicopathological factors in MTC

\section{Survivin expression}

XIAP expression

\begin{tabular}{|c|c|c|c|c|c|c|}
\hline Variables & Low, $n=32$ (\%) & High, $n=47(\%)$ & $P$-value & Low, $n=42(\%)$ & High, $n=37(\%)$ & $P$-value \\
\hline Age, mean \pm s.d. & $48.5 \pm 18.7$ & $50.5 \pm 18.6$ & 0.3021 & $49 \pm 20.7$ & $49 \pm 19.3$ & 0.9849 \\
\hline \multicolumn{7}{|l|}{ Gender } \\
\hline Male & $15(47)$ & $23(49)$ & & $19(45)$ & $19(51)$ & \\
\hline Female & $17(53)$ & $24(51)$ & 1.0 & $23(55)$ & $18(49)$ & 0.6550 \\
\hline \multicolumn{7}{|l|}{ Tumour stage } \\
\hline $\mathrm{T} 1 / 2$ & $29(91)$ & $31(66)$ & & $37(88)$ & $23(62)$ & \\
\hline $\mathrm{T} 3 / 4$ & $3(9)$ & $16(34)$ & 0.0153 & $5(12)$ & $14(38)$ & 0.0089 \\
\hline \multicolumn{7}{|c|}{ Lymph node metastasis } \\
\hline NO & $21(66)$ & $16(34)$ & & $26(62)$ & $11(30)$ & \\
\hline $\mathrm{N} 1 \mathrm{a} / \mathrm{b}$ & 11 (34) & $31(66)$ & 0.0068 & $16(38)$ & $26(70)$ & 0.0065 \\
\hline \multicolumn{7}{|c|}{ Distant metastasis } \\
\hline $\mathrm{MO}$ & $29(91)$ & $30(64)$ & & $27(64)$ & $28(76)$ & \\
\hline M1 & $3(9)$ & $17(36)$ & 0.0084 & $15(36)$ & $9(24)$ & 0.3311 \\
\hline \multicolumn{7}{|l|}{ UICC stage } \\
\hline UICC I/II & $20(62.5)$ & $16(34)$ & & $25(60)$ & $11(30)$ & \\
\hline \multirow[t]{2}{*}{ UICC III/IV } & $12(37.5)$ & $31(66)$ & 0.0208 & $17(40)$ & $26(70)$ & 0.0124 \\
\hline & Low, $n=24$ (\%) & High, $n=35$ (\%) & & Low, $n=27$ (\%) & High, $n=32$ (\%) & \\
\hline \multicolumn{7}{|c|}{ Calcitonin basal blood level } \\
\hline Normal & 9 (37.5) & $3(9)$ & & 5 (19) & 7 (22) & \\
\hline \multirow[t]{2}{*}{ Elevated } & $15(62.5)$ & $32(91)$ & 0.0095 & $22(81)$ & $25(78)$ & 1.0 \\
\hline & Low, $n=32(\%)$ & High, $n=39$ (\%) & & Low, $n=38$ (\%) & High, $n=33$ (\%) & \\
\hline \multicolumn{7}{|l|}{ Genetic } \\
\hline Sporadic & $13(41)$ & $24(62)$ & & $15(39)$ & $22(67)$ & \\
\hline MEN2A & 19 (59) & $15(38)$ & 0.0980 & $23(61)$ & 11 (33) & 0.0321 \\
\hline
\end{tabular}

A

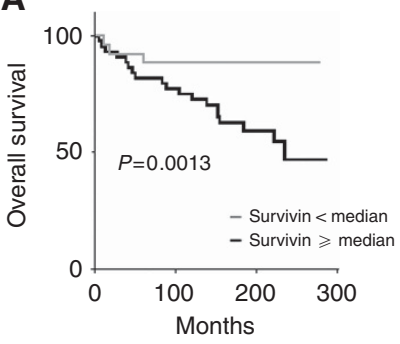

C

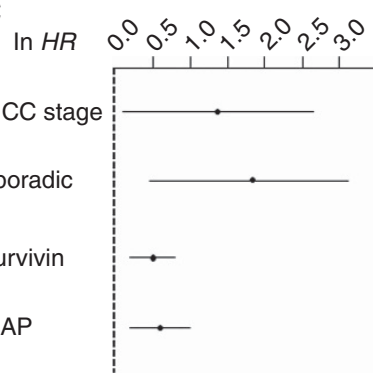

B

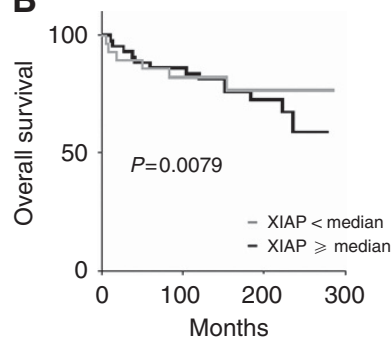

D

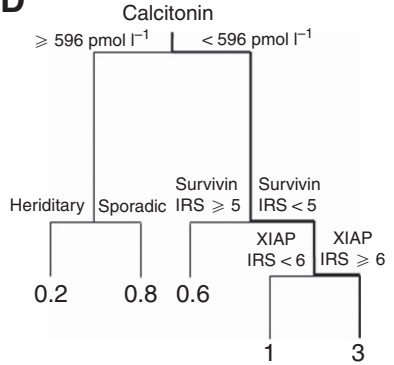

Figure 3. Kaplan-Meier curves for overall survival according to the IRS for survivin and XIAP. Based on the IRS of (A) survivin or (B) XIAP, specimens were classified into samples with high ( $\geqslant$ median) and low ( $<$ median) expression levels. (C) Summarises $\mathrm{HR}$ and $\mathrm{Cl}$ of the multivariate analysis after In transformation. (D) Survival regression tree analysis was performed to identify subgroups of patients with a high risk of death. Numbers under the vertical lines represent HRs of the given constellation.

expression (IRS $\geqslant 6$ ) had three times the risk of dying over the observed period of time, as compared with the other patients (Figure 3D).

\section{Table 3A. Overall survival: univariate analysis}

\begin{tabular}{|l|c|c|c|}
\hline Variables & HR & Cl (lower-upper 95\%) & $P$-value \\
\hline Age & 2.939 & $1.256-6.823$ & 0.0132 \\
\hline Sex & 1.488 & $0.6425-3433$ & 0.3535 \\
\hline T1/2 vs T3/4 & 2.176 & $0.9341-7.322$ & 0.0696 \\
\hline N0 vs N1a/b & 5.007 & $1.785-9.519$ & 0.0010 \\
\hline M0 vs M1 & 4.873 & $3.511-32.44$ & 0.0001 \\
\hline UICC I/II vs UICC III/IV & 4.187 & $1.461-7.780$ & 0.0046 \\
\hline Sporadic vs MEN2A & 5.094 & $1.558-9.886$ & 0.0039 \\
\hline Calcitonin basal blood level & 3.306 & $0.7676-14.24$ & 0.1085 \\
\hline Survivin expression & 3.765 & $1.166-6.568$ & 0.0214 \\
\hline XIAP expression & 1.239 & $0.4843-3.140$ & 0.6618 \\
\hline $\begin{array}{l}\text { Abbreviations: CI=confidence interval; HR=hazard ratio; XIAP=X-linked inhibitor of } \\
\text { apoptosis protein; UICC=Union internationale contre le cancer. }\end{array}$ \\
\hline
\end{tabular}

Table 3B. Overall survival: multivariate analysis after stepwise variable selection

\begin{tabular}{|l|c|c|c|}
\hline Variables & HR & Cl (lower-upper 95\%) & $\boldsymbol{P}$-value \\
\hline UICC I/II vs UICC III/IV & 3.950 & $1.143-13.645$ & 0.030 \\
\hline Sporadic vs MEN2A & 5.815 & $1.548-21.840$ & 0.009 \\
\hline Survivin expression & 1.616 & $1.207-2.162$ & 0.001 \\
\hline XIAP expression & 1.776 & $1.162-2.715$ & 0.008 \\
\hline
\end{tabular}

Abbreviations: $\mathrm{Cl}=$ confidence interval; $\mathrm{HR}=$ hazard ratio; $\mathrm{XIAP}=\mathrm{X}$-linked inhibitor of apoptosis protein; UICC = Union internationale contre le cancer.

\section{DISCUSSION}

Over the past years, great achievements have been made, bringing scientific benchwork to the patient's bed site and improving 
therapeutic results as well as quality of life. The progress of identifying strong prognostic biomarkers and later targeting them with their respective antagonists has led to paramount changes in patient treatment strategies (Miura et al, 2011; Rödel et al, 2012).

Approximately $50 \%$ of all patients with MTC harbour distant metastasis at the time of diagnosis, and systemic therapeutic agents are in high demand to treat the spreading disease (Hu et al, 2014). At the beginning of the twenty-first century, only conventional chemotherapeutics, mostly based on dacarbazin and doxorubicin, have been used in the treatment of advanced MTC (Vitale et al, 2001). However, in the past decade a new insight into the biology of MTC has been gained, which enabled oncologists for novel approaches in targeted therapy. Owing to the known biology of RET oncogene mutations in MTC, the main focus has been placed on tyrosine kinase inhibitors, for both hereditary and sporadic MTC (Lalami and Awada, 2011). However, only $40-50 \%$ of all patients with sporadic MTC have a somatic RET mutation and a consequently activated tyrosine kinase (Elisei et al, 2008). Therefore, especially for the remaining patients, research dealing with the commonly altered signalling pathways in oncogenesis is of great importance.

In this regard, inhibition of apoptosis is a hallmark feature of carcinoma cells. The regulation as well as the maintenance of a reasonable homeostasis in tissues and organs is a key physiological operation, largely depending on the complex interdependency of proliferation and apoptosis. However, during oncogenesis an imbalance between these two poles leads to an uncontrolled proliferation and metastatic spread (Obexer and Ausserlechner, 2014; Wan et al, 2014). In this context, several antiapoptotic proteins such as the IAP-family members have attracted considerable attention during the past decades. IAPs comprise a group of BIR-domain containing proteins that inhibit apoptosis, induce resistance to conventional chemotherapy or radiotherapy and are overexpressed in a wide variety of tumour entities (de Almagro and Vucic, 2012).

Thus far, little is known about the role of IAPs in the oncogenesis of MTC. To our knowledge, our study is the first that focused on the stage-dependent expression levels of survivin and XIAP in MTC and analysed their prognostic relevance. For our cohort, we could show that survivin and XIAP are two independent novel prognostic biomarkers in MTC. They both demonstrated a strong negative correlation with patients' overall survival in the multivariate analysis. Besides their association with a worse outcome in MTC patients, both survivin and XIAP correlated with more advanced tumour stages and a metastatic phenotype. Importantly, these results are in line with recent metaanalyses that underscored not only the prognostic relevance but also the association of survivin with a metastasised disease for colorectal and gastric carcinoma patients (Krieg et al, 2013a,b). A recent study by Selemetjev et al (2014) also demonstrated the close correlation between survivin and the presence of lymph node metastasis in papillary thyroid carcinoma. Similar results have been published for XIAP in several solid tumour entities, underscoring the relation between XIAP and a metastatic phenotype as well as poor prognosis (Ramp et al, 2004; Shi et al, 2008; Yim et al, 2014). In addition, Mehrotra et al (2010) demonstrated that survivin in a complex with XIAP was essential for the formation of distant metastasis. Functionally, this aspect is independent of their antiapoptotic properties and is caused by an activation of cell motility kinases FAK and Src via NF- $\kappa$ B.

Remarkably, high survivin expression in MTC was associated with elevated calcitonin basal blood levels, whereas this was not evident for XIAP. The observation that high serum calcitonin correlates with increased expression levels of survivin in MTC specimens supports the recently published data by Thomas and Shah (2005) who demonstrated in prostate carcinoma cell lines an induction of survivin by calcitonin, causing chemoresistance in vitro (Thomas and Shah, 2005; Thomas et al, 2007). This interdependency between survivin and calcitonin may be of unique importance in MTC as parafollicular C cells, the sole producers of the peptide hormone calcitonin, are the hosts from which MTC originates. Thus, the relationship between autocrine and paracrine signalling in which tumour cells secrete calcitonin that, upon binding to its receptor, induces antiapoptotic or promitotic signalling pathways are of great interest for the oncogenesis in MTC. This self-preserving cycle of autocrine secretion and selfstimulation may prove to be a key regulatory step and warrants further research in this field.

Interestingly, patients with sporadic MTC exhibited significantly higher expression levels of XIAP compared with the hereditary form. This emphasises again that certain subgroups of a carcinoma may establish different molecular pathways by which they ensure their survival and progression. However, as shown in the decision tree, it sometimes might be the combination of certain biomarkers and the actual given condition of the individual patient that increases the risk of death considerably. Although the decision tree is solely an exploratory statistical method, it still underscores the importance of a broad panel of prognostic biomarkers to describe and foresee the tumour's biology, which is as individual as the patient. Especially, grouping of patients with different characteristics will lead us to a more profound understanding of the disease and ultimately to a more individualised medicine and the chance to tailor our therapeutic approaches to the individual needs of our patients (Schwaederle et al, 2015).

Encouraging results have been published concerning the antagonising effect of chemical compounds against survivin and XIAP in subgroups of thyroid carcinoma. Mehta et al (2015) demonstrated that the survivin inhibitor YM155 could significantly reduce cellular proliferation in anaplastic thyroid carcinoma cell lines, inhibit proliferation and metastasis in vivo and prolong survivial. Similarly for XIAP, Hussain et al (2015) showed that antagonising of XIAP by small-molecule Embelin caused growth inhibition and apoptosis in papillary thyroid carcinoma cell lines and induced tumour regression in a nude mouse model. Thus, both studies underscore the functional aspects of survivin and XIAP as novel biomarkers and their potential therapeutic implications.

Despite the limitations of the retrospective design of our study, our results fit perfectly into the emerging landscape of IAP interaction. Both biomarkers with their distinct expression profiles and negative prognostic implications can therefore be considered as new viable therapeutic options in MTC. However, more research, especially on the functional aspects of survivin and XIAP in MTC, needs to be carried out to further improve our understanding of their role in MTC biology and to enable us for a more personalised therapeutic approach in the future.

\section{ACKNOWLEDGEMENTS}

The study was supported, in part, by a grant from the Deutsche Forschungsgemeinschaft (KR 3496/2-1 to AK).

\section{CONFLICT OF INTEREST}

The authors declare no conflict of interest.

\section{REFERENCES}

American Thyroid Association Guidelines Task Force Kloos RT, Eng C, Evans DB, Francis GL, Gagel RF, Gharib H, Moley JF, Pacini F, Ringel MD, Schlumberger M, Wells SA (2009) Medullary thyroid cancer: 
management guidelines of the American Thyroid Association. Thyroid 19: 565-612.

Ball DW (2009) American Thyroid Association guidelines for management of medullary thyroid cancer: an adult endocrinology perspective. Thyroid 19: 547-550.

Bertrand MJM, Doiron K, Labbé K, Korneluk RG, Barker PA, Saleh M (2009) Cellular inhibitors of apoptosis cIAP1 and cIAP2 are required for innate immunity signaling by the pattern recognition receptors NOD1 and NOD2. Immunity 30: 789-801.

Blume-Jensen P, Hunter T (2001) Oncogenic kinase signalling. Nature 411: 355-365.

Cupisti K, Lehwald N, Anlauf M, Riemer J, Werner TA, Krieg A, Witte J, Chanab A, Baldus SE, Krausch M, Raffel A, Herdter C, Schott M, Knoefel WT (2014) Encapsulation status of papillary thyroid microcarcinomas is associated with the risk of lymph node metastases and tumor multifocality. Horm Metab Res 46: 138-144.

de Almagro MC, Vucic D (2012) The inhibitor of apoptosis (IAP) proteins are critical regulators of signaling pathways and targets for anti-cancer therapy. Exp Oncol 34: 200-211.

Donis-Keller H, Dou S, Chi D, Carlson KM, Toshima K, Lairmore TC, Howe JR, Moley JF, Goodfellow P, Wells SA (1993) Mutations in the RET proto-oncogene are associated with MEN 2A and FMTC. Hum Mol Genet 2: 851-856.

Dralle H, Musholt TJ, Schabram J, Steinmüller T, Frilling A, Simon D, Goretzki PE, Niederle B, Scheuba C, Clerici T, Hermann M, Kußmann J, Lorenz K, Nies C, Schabram P, Trupka A, Zielke A, Karges W, Luster M, Schmid KW, Vordermark D, Schmoll H-J, Mühlenberg R, Schober O, Rimmele H, Machens A. German Societies of General and Visceral Surgery, Endocrinology, Nuclear, Medicine, Pathology, Radiooncology, Oncological Hematology and the German Thyroid Cancer Patient Support Organization Ohne Schilddrüse leben e.V. (2013) German Association of Endocrine Surgeons practice guideline for the surgical management of malignant thyroid tumors. Langenbecks Arch Surg 398: 347-375.

Elisei R, Cosci B, Romei C, Bottici V, Renzini G, Molinaro E, Agate L, Vivaldi A, Faviana P, Basolo F, Miccoli P, Berti P, Pacini F, Pinchera A (2008) Prognostic significance of somatic RET oncogene mutations in sporadic medullary thyroid cancer: a 10-year follow-up study. J Clin Endocrinol Metab 93: 682-687.

Eng C, Clayton D, Schuffenecker I, Lenoir G, Cote G, Gagel RF, van Amstel HK, Lips CJ, Nishisho I, Takai SI, Marsh DJ, Robinson BG, Frank-Raue K, Raue F, Xue F, Noll WW, Romei C, Pacini F, Fink M, Niederle B, Zedenius J, Nordenskjöld M, Komminoth P, Hendy GN, Mulligan LM (1996) The relationship between specific RET protooncogene mutations and disease phenotype in multiple endocrine neoplasia type 2. International RET mutation consortium analysis. JAMA 276: 1575-1579.

Goossens-Beumer IJ, Zeestraten ECM, Benard A, Christen T, Reimers MS, Keijzer R, Sier CFM, Liefers GJ, Morreau H, Putter H, Vahrmeijer AL, van de Velde CJH, Kuppen PJK (2014) Clinical prognostic value of combined analysis of Aldh1, Survivin, and EpCAM expression in colorectal cancer. Br J Cancer 110: 2935-2944.

Gu Y, Jin S, Wang F, Hua Y, Yang L, Shu Y, Zhang Z, Guo R (2014) Clinicopathological significance of PI3K, Akt and survivin expression in gastric cancer. Biomed Pharmacother 68: 471-475.

Gyrd-Hansen M, Meier P (2010) IAPs: from caspase inhibitors to modulators of NF-kappaB, inflammation and cancer. Nat Rev Cancer 10: 561-574.

Hu MI, Ying AK, Jimenez C (2014) Update on medullary thyroid cancer. Endocrinol Metab Clin N Am 43: 423-442.

Hussain AR, Bu R, Ahmed M, Jehan Z, Beg S, Al-Sobhi S, Al-Dayel F, Siraj AK, Uddin S, Al-Kuraya KS (2015) Role of X-linked inhibitor of apoptosis as a prognostic marker and therapeutic target in papillary thyroid carcinoma. J Clin Endocrinol Metab 100: E974-E985.

Ito $\mathrm{Y}$, Kihara M, Hirokawa M, Takamura Y, Kobayashi K, Miya A, Miyauchi A (2012) Validity of 6th edition of UICC TNM classification system for medullary thyroid carcinoma: a proposal for intraoperative evaluation of T category. Endocr J 59: 407-416.

Krieg A, Baseras B, Tomczak M, Verde PE, Stoecklein NH, Knoefel WT (2013a) Role of survivin as prognostic and clinicopathological marker in gastric cancer: a meta-analysis. Mol Biol Rep 40: 5501-5511.

Krieg A, Correa RG, Garrison JB, Le Negrate G, Welsh K, Huang Z, Knoefel WT, Reed JC (2009) XIAP mediates NOD signaling via interaction with RIP2. Proc Natl Acad Sci USA 106: 14524-14529.
Krieg A, Reed JC (2010) IAPs and their emergent role in NLR signaling. Cell Cycle 9: 426-427.

Krieg A, Werner TA, Verde PE, Stoecklein NH, Knoefel WT (2013b) Prognostic and clinicopathological significance of survivin in colorectal cancer: a meta-analysis. PLoS One 8: e65338.

Lalami Y, Awada A (2011) Recurrent thyroid cancer: a molecular-based therapeutic breakthrough. Curr Opin Oncol 23: 235-240.

Leboulleux SS, Baudin EE, Travagli J-PJ, Schlumberger MM (2004) Medullary thyroid carcinoma. Clin Endocrinol (Oxf) 61: 299-310.

McShane LM, Altman DG, Sauerbrei W, Taube SE, Gion M, Clark GM. Statistics Subcommittee of the NCI-EORTC Working Group on Cancer Diagnostics (2005) Reporting recommendations for tumor marker prognostic studies (REMARK). J Natl Cancer Inst 97: 1180-1184.

Mehrotra S, Languino LR, Raskett CM, Mercurio AM, Dohi T, Altieri DC (2010) IAP regulation of metastasis. Cancer Cell 17: 53-64.

Mehta A, Zhang L, Boufraqech M, Liu-Chittenden Y, Zhang Y, Patel D, Davis S, Rosenberg A, Ylaya K, Aufforth R, Li Z, Shen M, Kebebew E (2015) Inhibition of survivin with YM155 induces durable tumor response in anaplastic thyroid cancer. Clin Cancer Res 21: 4123-4132.

Miller LK (1999) An exegesis of IAPs: salvation and surprises from BIR motifs. Trends Cell Biol 9: 323-328.

Miura K, Fujibuchi W, Ishida K, Naitoh T, Ogawa H, Ando T, Yazaki N, Watanabe K, Haneda S, Shibata C, Sasaki I (2011) Inhibitor of apoptosis protein family as diagnostic markers and therapeutic targets of colorectal cancer. Surg Today 41: 175-182.

Mizutani Y, Nakanishi H, Li YN, Matsubara H, Yamamoto K, Sato N, Shiraishi T, Nakamura T, Mikami K, Okihara K, Takaha N, Ukimura O, Kawauchi A, Nonomura N, Bonavida B, Miki T (2007) Overexpression of XIAP expression in renal cell carcinoma predicts a worse prognosis. Int J Oncol 30: 919-925.

Obexer P, Ausserlechner MJ (2014) X-linked inhibitor of apoptosis protein - a critical death resistance regulator and therapeutic target for personalized cancer therapy. Front Oncol 4: 197.

Qi X-P, Ma J-M, Du Z-F, Ying R-B, Fei J, Jin H-Y, Han J-S, Wang J-Q, Chen X-L, Chen C-Y, Liu W-T, Lu J-J, Zhang J-G, Zhang X-N (2011) RET germline mutations identified by exome sequencing in a Chinese multiple endocrine neoplasia type $2 \mathrm{~A} /$ familial medullary thyroid carcinoma family. PLoS One 6: e20353.

R Development Core Team (2014) R: A Language and Environment for Statistical Computing. The R foundation for statistical computing: Vienna, Austria. Available from http://www.R-project.org/.

Ramp U, Krieg T, Caliskan E, Mahotka C, Ebert T, Willers R, Gabbert HE, Gerharz CD (2004) XIAP expression is an independent prognostic marker in clear-cell renal carcinomas. Hum Pathol 35: 1022-1028.

Remmele W, Hildebrand U, Hienz HA, Klein PJ, Vierbuchen M, Behnken LJ, Heicke B, Scheidt E (1986) Comparative histological, histochemical, immunohistochemical and biochemical studies on oestrogen receptors, lectin receptors, and Barr bodies in human breast cancer. Virchows Arch A 409: $127-147$

Rosa J, Canovas P, Islam A, Altieri DC, Doxsey SJ (2006) Survivin modulates microtubule dynamics and nucleation throughout the cell cycle. Mol Biol Cell 17: 1483-1493.

Rödel F, Sprenger T, Kaina B, Liersch T, Rödel C, Fulda S, Hehlgans S (2012) Survivin as a prognostic/predictive marker and molecular target in cancer therapy. Curr Med Chem 19: 3679-3688.

Schwaederle M, Zhao M, Lee JJ, Eggermont AM, Schilsky RL, Mendelsohn J, Lazar V, Kurzrock R (2015) Impact of precision medicine in diverse cancers: a meta-analysis of phase II clinical trials. J Clin Oncol 33: $3817-25$.

Selemetjev S, Dencic TI, Marecko I, Jankovic J, Paunovic I, Savin S, Cvejic D (2014) Evaluation of survivin expression and its prognostic value in papillary thyroid carcinoma. Pathol Res Pract 210: 30-34.

Shi Y-H, Ding W-X, Zhou J, He J-Y, Xu Y, Gambotto AA, Rabinowich H, Fan J, Yin X-M (2008) Expression of X-linked inhibitor-of-apoptosis protein in hepatocellular carcinoma promotes metastasis and tumor recurrence. Hepatology 48: 497-507.

Takahashi M (1995) Oncogenic activation of the ret protooncogene in thyroid cancer. Crit Rev Oncog 6: 35-46.

Tenev T, Bianchi K, Darding M, Broemer M, Langlais C, Wallberg F, Zachariou A, Lopez J, MacFarlane M, Cain K, Meier P (2011) The Ripoptosome, a signaling platform that assembles in response to genotoxic stress and loss of IAPs. Mol Cell 43: 432-448. 
Thomas S, Muralidharan A, Shah GV (2007) Knock-down of calcitonin receptor expression induces apoptosis and growth arrest of prostate cancer cells. Int J Oncol 31: 1425-1437.

Thomas S, Shah G (2005) Calcitonin induces apoptosis resistance in prostate cancer cell lines against cytotoxic drugs via the Akt/survivin pathway. Cancer Biol Ther 4: 1226-1233.

Tuttle RM, Ball DW, Byrd D, Daniels GH, Dilawari RA, Doherty GM, Duh Q-Y, Ehya H, Farrar WB, Haddad RI, Kandeel F, Kloos RT, Kopp P, Lamonica DM, Loree TR, Lydiatt WM, McCaffrey J, Olson JA, Parks L, Ridge JA, Shah JP, Sherman SI, Sturgeon C, Waguespack SG, Wang TN, Wirth LJ (2010) Medullary carcinoma. Compr Cancer 8: 512-30.

Vaux DL, Silke J (2003) Mammalian mitochondrial IAP binding proteins. Biochem Biophys Res Commun 304: 499-504.

Vitale G, Caraglia M, Ciccarelli A, Lupoli G, Abbruzzese A, Tagliaferri P, Lupoli G (2001) Current approaches and perspectives in the therapy of medullary thyroid carcinoma. Cancer 91: 1797-1808.

Waligórska-Stachura J, Andrusiewicz M, Sawicka-Gutaj N, Biczysko M, Jankowska A, Kubiczak M, Czarnywojtek A, Wrotkowska E, Ruchała M (2014) Survivin delta Ex3 overexpression in thyroid malignancies. PLoS One 9: e100534.
Wan Y, Liu T, Hou X, Dun Y, Guan P, Fang H (2014) Antagonists of IAP proteins: novel anti-tumor agents. Curr Med Chem 21: 3877-3892.

Wells SA, Pacini F, Robinson BG, Santoro M (2013) Multiple endocrine neoplasia type 2 and familial medullary thyroid carcinoma: an update. $J$ Clin Endocrinol Metab 98: 3149-3164.

Wu LS, Roman SA, Sosa JA (2011) Medullary thyroid cancer: an update of new guidelines and recent developments. Curr Opin Oncol 23: 22-27.

Xu Y-C, Liu Q, Dai J-Q, Yin Z-Q, Tang L, Ma Y, Lin X-L, Wang H-X (2014) Tissue microarray analysis of X-linked inhibitor of apoptosis (XIAP) expression in breast cancer patients. Med Oncol 31: 764.

Yim JH, Kim WG, Jeon MJ, Han JM, Kim TY, Yoon JH, Hong SJ, Song DE, Gong G, Shong YK, Kim WB (2014) Association between expression of $\mathrm{X}$-linked inhibitor of apoptosis protein and the clinical outcome in a BRAF V600E-prevalent papillary thyroid cancer population. Thyroid 24: 689-694.

This work is published under the standard license to publish agreement. After 12 months the work will become freely available and the license terms will switch to a Creative Commons AttributionNonCommercial-Share Alike 4.0 Unported License.

Supplementary Information accompanies this paper on British Journal of Cancer website (http://www.nature.com/bjc) 